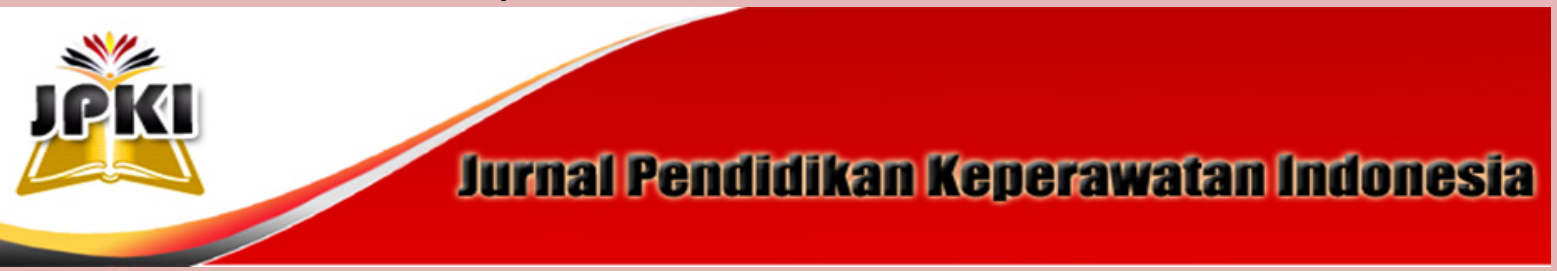

Journal homepage : http://ejournal.upi.edu/index.php/JPKI

\title{
GAMBARAN KEPATUHAN PASIEN TUBERKULOSIS PARU TERHADAP REGIMEN TERAPEUTIK DI PUSKESMAS PADASUKA KOTA BANDUNG
}

\author{
Safii ${ }^{1}$, Suci Tuty Putri ${ }^{2}$, Tirta Adikusuma Suparto ${ }^{3}$ \\ ${ }^{1,2,3}$ Prodi DIII Keperawatan FPOK Universitas Pendidikan Indonesia \\ Email : suci.putri@upi.edu
}

\begin{abstract}
ABSTRAK
Tuberkulosis merupakan penyakit menular bahkan bisa menyebabkan kematian, penyakit ini menyebar melalui droplet orang yang telah terinfeksi basil tuberkulosis. Tuberkulosis masih menjadi salah satu pembunuh utama bagi manusia, jika tidak diobati dengan baik maka penyakit ini dapat menyebabkan kematian pada hampir setengah kasus selama 5 tahun setelah menderita penyakit ini. Kepatuhan rata-rata pasien pada pengobatan jangka panjang terhadap penyakit kronis di negara maju hanya sebesar 50\% sedangkan di negara berkembang jumlah tersebut bahkan lebih rendah. Ketidakpatuhan pasien dalam pengobatan merupakan masalah kesehatan yang serius dan sering terjadi pada pasien dengan penyakit kronis, seperti pada penyakit Tuberkulosis Paru. Penelitian ini bertujuan untuk mengetahui kepatuhan pasien Tuberkulosis Paru di Puskesmas Padasuka Kecamatan Cibeunying Kidul Kota Bandung. Desain dalam penelitian ini adalah deskriptif kuantitatif. Pengambilan data dilakukan dengan menggunakan kuesioner dan teknik accidental sampling dengan jumlah sampel 21 orang. Hasil penelitian menunjukkan bahwa mayoritas pasien Tuberkulosis Paru memiliki kepatuhan terhadap regimen terapeutik yaitu diperoleh 16 orang $(76 \%)$, yang tidak patuh diperoleh 5 orang (24\%). Alasan yang paling banyak diungkapkan oleh responden yang patuh adalah karena ingin cepat sembuh dari penyakitnya, bisa beraktivitas kembali seperti biasa sebelum sakit, dukungan dari keluarga responden dan informasi yang didapatkan dari petugas puskesmas sangat baik sehingga termotivasi untuk patuh meminum obat. Diharapkan semua pihak diantaranya keluarga pasien, pemerintah dan tenaga kesehatan untuk lebih memotivasi pasien Tuberkulosis Paru untuk kepatuhan berobat dan melakukan pendidikan kesehatan terhadap pasien Tuberkulosis Paru untuk meningkatkan keberhasilan terapi pengobatan.
\end{abstract}

Kata kunci : Kepatuhan, Regimen Terapeutik dan Tuberkulosis Paru.

\section{ABSTRACT}

Tuberculosis is an infectious disease that can cause death, disease is spread through droplet of people who have been infected with the tuberculosis bacillus. Tuberculosis is one of the major killer of humans at this time, the disease can cause death in almost half of cases for 5 years after the disease. The average patient compliance in long-term treatment of chronic diseases in developed 
countries is only 50\%, while in developing countries the number is lower. Noncompliance of patients in the treatment of a serious health problem and often occurs in patients with chronic diseases, such as Tuberculosis disease. This study aims to determine the compliance of pulmonary Tuberculosis patients in sub-district Puskesmas Padasuka Cibeunying Bandung Kidul. Design of this research is quantitative descriptive. Data were collected using questionnaires and accidental sampling with a sample of 21 people. The results showed that the majority of patients with pulmonary tuberculosis have adherence to therapeutic regimens is obtained by 16 people (76\%), which do not comply obtained 5 people (24\%). The most reason expressed by respondents who are obedient because they want toget well from his illness, can do aktivity before ill, the support of family respondents and the information obtained from health center personnel very good so motivated to obey taking drugs. It is hoped all parties including the patient's family, the government and health professionals to better motivate patients for pulmonary Tuberculosis treatment compliance and conduct health education for patients with pulmonary Tuberculosis to increase the therapeutic efficacy of treatment.

Keywords: Compliance, Therapeutic Regimen and Tuberculosis Lung.

\section{PENDAHULUAN}

Tuberkulosis $(\mathrm{Tb})$ merupakan penyakit menular bahkan bisa menyebabkan kematian, penyakit ini menyebar melalui droplet orang yang telah terinfeksi basil tuberkulosis (Depkes RI, 2013). Masalah Tuberkulosis didunia diperkirakan sekitar sepertiga penduduk dunia telah terinfeksi oleh Mycobacterium Tuberculosis. Pada tahun 1995, diperkirakan ada 9 juta pasien $\mathrm{Tb}$ baru dan 3 juta kematian akibat $\mathrm{Tb}$ diseluruh dunia. Diperkirakan 95\% kasus Tb dan 98\% kematian akibat $\mathrm{Tb}$ didunia, terjadi pada negara-negara berkembang. Demikian juga kematian wanita akibat $\mathrm{Tb}$ lebih banyak dari pada kematian karena kehamilan, persalinan, dan nifas (Depkes RI, 2011)

Tuberkulosis merupakan masalah global dimana World Health Organization (WHO) memperkirakan setiap tahun masih terdapat sekitar sembilan juta penderita $\mathrm{Tb}$ paru baru dengan kematian sekitar 1,1 sampai 1,6 juta orang termasuk kasus $\mathrm{Tb}$ dengan HIV positif. Penyakit $\mathrm{Tb}$ masih menjadi pembunuh nomor dua didunia dari seluruh penyakit infeksi setelah HIV yang diperkirakan telah membunuh 1,8 juta tahun 2008 (Depkes RI, 2009).
Tuberkulosis sampai saat ini masih menjadi tantangan dalam masalah kesehatan masyarakat baik global maupun nasional. Berdasarkan Global Tuberculosis Control WHO Report tahun 2007, Indonesia berada di peringkat ketiga jumlah kasus tuberkulosis terbesar di dunia (528.000 kasus) setelah India dan Cina. Dalam laporan serupa tahun 2009, Indonesia mengalami kemajuan menjadi peringkat kelima (429.730 kasus) setelah India, Cina, Afrika Selatan dan Nigeria (Depkes RI, 2011).

Jumlah kasus tertinggi yang dilaporkan terdapat di provinsi dengan jumlah penduduk yang besar yaitu Jawa Barat, Jawa Timur, dan Jawa Tengah. Kasus baru Batang Tahan Asam positif (BTA) ditiga provinsi tersebut hampir sebesar 40\% dari jumlah seluruh kasus baru di Indonesia. Pravelensi Tb berdasarkan diagnosis sebesar $0,4 \%$ dari jumlah penduduk. Dengan kata lain, rata-rata tiap 100.000 penduduk Indonesia terdapat 400 orang yang didiagnosis kasus $\mathrm{Tb}$ oleh tenaga kesehatan. Penyakit $\mathrm{Tb}$ paru ditanyakan pada responden untuk kurun waktu $<1$ tahun berdasarkan diagnosis yang ditegakkan oleh tenaga kesehatan melalui pemeriksaan dahak, foto thoraks atau keduanya. Hasil Riskesdas 2013 tersebut tidak berbeda dengan Riskesdas 2007 yang 
menghasilkan angka prevelensi $\mathrm{Tb}$ paru $0,4 \%$ (Riskesdas, 2013).

Hasil laporan Dinas Kesehatan Kota Bandung 2011, dari puskesmas yang ada di Kota Bandung pada tahun 2011 ditemukan penderita Tuberkulosis secara klinis dan laboratoris sebanyak 2.482 kasus. Bila dibandingkan dengan tahun lalu, penemuan kasus Tb sebesar 2.506 kasus, sehingga berarti terjadi penurunan penemuan kasus sebesar 124 kasus. Penderita Tuberkulosis dengan Tb BTA (+) sebanyak 1.137 bila dibandingkan dengan tahun lalu terdapat peningkatan yaitu 69 kasus. Penderita Tb BTA (+) sebanyak 1.137 penderita tersebut yang $1.075 \quad(94,54 \%)$ diantaranya telah diobati (Dinkes Kota Bandung, 2011).

Tuberkulosis paru merupakan penyakit menular langsung yang disebabkan oleh kuman $\mathrm{Tb}$ (Mycobacterium tuberculosis). Gejala utama adalah batuk selama 2 minggu atau lebih, batuk disertai dengan gejala tambahan yaitu dahak, dahak bercampur darah, sesak nafas, badan lemas, nafsu makan menurun, berat badan menurun, malaise, berkeringat malam hari tanpa kegiatan fisik, demam lebih dari 1 bulan (Riskesdas, 2013).

Tuberkulosis masih menjadi salah satu pembunuh utama bagi manusia, jika tidak diobati dengan baik maka penyakit ini dapat menyebabkan kematian pada hampir setengah kasus selama 5 tahun setelah menderita penyakit ini. Adanya kontak dengan Batang Tahan Asam (BTA) positif dapat menjadi sumber penularan yang berbahaya karena berdasarkan penelitian akan menularkan sekitar $65 \%$ orang disekitarnya. Sumber penularan adalah pasien Tb Paru dengan BTA positif terutama pada waktu batuk atau bersin, dimana pasien menyebarkan kuman ke udara dalam bentuk percikan dahak (droplet nuclei) jika tidak segera diobati maka dalam jangka waktu satu tahun akan menular ke 10- 15 orang (Depkes RI, 2008).
Kepatuhan rata-rata pasien pada pengobatan jangka panjang terhadap penyakit kronis di negara maju hanya sebesar 50\% sedangkan di negara berkembang jumlah tersebut bahkan lebih rendah. Ketidakpatuhan pasien dalam pengobatan merupakan masalah kesehatan yang serius dan sering terjadi pada pasien dengan penyakit kronis, seperti pada penyakit tuberkulosis paru. Banyak faktor yang berhubungan dengan kepatuhan terhadap terapi $\mathrm{Tb}$ paru, termasuk karakteristik pasien, hubungan antara petugas pelayanan kesehatan dan pasien, regimen terapi dan sistem penyelenggara pelayanan kesehatan (Depkes RI, 2008).

Berdasarkan studi pendahuluan yang dilakukan pada tanggal 9 Mei 2015 lalu di Puskesmas Padasuka Kecamatan Cibeunying Kidul Kota Bandung, dengan melakukan wawancara mengenai kepatuhan minum obat terhadap 4 orang pasien $\mathrm{Tb}$ paru yang sedang melakukan pengobatan rutin setiap satu minggu sekali. Diketahui bahwa 2 dari 4 pasien Tb paru mengatakan masih tidak patuh minum obat dengan sesuai jadwal yang sudah ditentukan oleh tenaga medis. Oleh karena itu peneliti ingin meneliti lebih lanjut mengenai gambaran kepatuhan pasien $\mathrm{Tb}$ paru terhadap regimen terapeutik di Puskesmas Padasuka Kecamatan Cibeunying Kidul Kota Bandung.

\section{METODE}

Desain penelitian yang digunakan dalam penelitian ini adalah deskriptif kuantitatif. Pada penelitian ini populasi yang digunakan adalah seluruh pasien $\mathrm{Tb}$ paru yang kontrol dan berobat di Puskesmas Padasuka, Kecamatan Cibeunying Kidul, Kota Bandung Jawa Barat yang melakukan pengobatan setiap satu kali dalam seminggu mencakup kunjungan baru dan lama dengan jumlah 60 pasien. Dalam penelitian ini, metode pengambilan sampel yang digunakan adalah metode non-probability sampling dan pemilihan sampel yang diambil ditentukan dengan teknik accidental sampling 
yaitu teknik penentuan sampel secara kebetulan, yaitu pasien $\mathrm{Tb}$ paru yang kontrol dan berobat di Puskesmas Padasuka, Kecamatan Cibeunying Kidul, Kota Bandung Jawa Barat dimana penelitian ini dilakukan selama 2 minggu pada tanggal 26 Mei 2015 dan 09 Juni 2015 dengan jumlah sampel yang diperoleh 21 responden. Lokasi penelitian ini dilaksanakan di Puskesmas Padasuka, Kecamatan Cibeunying Kidul, Kota Bandung Jawa Barat. Pengambilan data dilakukan 2 minggu pada tanggal 26 Mei 2015 dan 09 Juni 2015 di Puskesmas Padasuka, Kecamatan Cibeunying Kidul Kota Bandung pada pasien Tb Paru.

Instrumen penelitian yang digunakan adalah kuisioner tertutup. Kuisioner tertutup adalah kuisioner yang disusun dengan menyediakan pilihan jawaban lengkap sehingga pengisi hanya tinggal memberi tanda pada jawaban yang dipilih (Risal, 2011). Kuisioner ini digunakan untuk mengukur gambaran kepatuhan pasien Tb Paru terhadap regimen terapeutik. Dalam kuisioner ini menggunakan pilihan jawaban "YA" atau "TIDAK". Apabila memilih jawaban "YA" maka mendapat skor 0 dan apabila memilih jawaban "TIDAK" mendapat skor 1 .

Penelitian ini menggunakan kuesioner kepatuhan berobat pasien $\mathrm{Tb}$ paru sebelumnya yang dilakukan oleh (Hayati, 2011). hasil uji validitas kuesioner tersebut menunjukan korelasi positif dan memberikan nilai $\mathrm{r}_{\text {hitung }}$ (pearson correlation) yang lebih besar dibandingkan dengan $r_{\text {tabel }}(0,444)$. Oleh karena itu, kuesioner dapat dinyatakan valid. Sementara itu, uji reabilitasnya memberikan hasil bahwa nilai cronbach's alpha yaitu 0,718. Dengan demikian kuesioner dapat dinyatakan reliabel.

\section{HASIL}

1. Karakteristik responden
Karakteristik responden dalam penelitian ini meliputi umur responden dan jenis kelamin sebanyak 21 responden.

Tabel 4.1 Distribusi Frekuensi Responden Berdasarkan Umur dan Jenis Kelamin $(\mathbf{n}=\mathbf{2 1})$

\begin{tabular}{llll}
\hline $\mathbf{N}$ & \multicolumn{1}{c}{ Kriteria } \\
o & Responden & F & \% \\
\hline 1 & Umur : & & \\
& 17-25 tahun & 1 & 5 \\
& 26-35 tahun & 6 & 25 \\
& $36-45$ tahun & 3 & 15 \\
& $46-55$ tahun & 11 & $\mathbf{5 4}$ \\
& & & \\
\hline 2 & Jenis & & \\
& Kelamin : & 15 & $\mathbf{7 1}$ \\
& Laki-laki & 6 & 29 \\
& Perempuan & & \\
\hline
\end{tabular}

Berdasarkan tabel 4.1 dapat diketahui bahwa usia pasien Tb paru di Puskesmas Padasuka Kecamatan Cibeunying Kidul pada tahun 2015 sebagian besar berusia 46-55 tahun yaitu sekitar 11 orang (54\%), dan berusia 26-35 tahun 6 orang $(25 \%)$.

Berdasarkan data jenis kelamin pasien $\mathrm{Tb}$ paru di Puskesmas Padasuka Kecamatan Cibeunying Kidul Kota Bandung didominasi oleh pasien $\mathrm{Tb}$ Paru laki-laki sebanyak 15 orang $(71 \%)$ dan pasien TB paru perempuan sebanyak 6 orang $(29 \%)$.

Tabel 4.2 Distribusi Frekuensi Responden Berdasarkan Gambaran Kepatuhan Pada Pasien Tb Paru Terhadap Regimen 


\section{Terapeutik Di uskesmas Padasuka Kecamatan Cibeunying Kidul Kota Bandung $(\mathrm{n}=\mathbf{2 1})$}

\begin{tabular}{lcc}
\hline $\begin{array}{l}\text { Kriteria } \\
\text { kepatuhan }\end{array}$ & F & \% \\
\hline Patuh & 16 & $\mathbf{7 6 \%}$ \\
& & $24 \%$ \\
Tidak patuh & 5 & $100 \%$ \\
\hline Total & 21 & \\
\end{tabular}

Berdasarkan tabel 4.2 diatas, dapat diketahui gambaran kepatuhan pada pasien $\mathrm{Tb}$ paru terhadap regimen terapeutik di Puskesmas Padasuka Kecamatan Cibeunying Kidul Kota Bandung sebagian besar berada pada kategori patuh, yaitu sebanyak 16 orang (76\%), sisanya kategori tidak patuh sebanyak 5 orang (24\%).

\section{PEMBAHASAN}

\begin{abstract}
Kepatuhan merupakan fenomena multidimensi yang ditentukan oleh lima dimensi yang saling terkait, yaitu faktor pasien, faktor terapi, faktor sistem kesehatan, faktor lingkungan, dan faktor sosial ekonomi. Semua faktor adalah faktor penting dalam mempengaruhi kepatuhan sehingga tidak ada pengaruh lebih kuat dari faktor lainnya (WHO, 2003).
\end{abstract}

Berdasarkan hasil penelitian, pasien $\mathrm{Tb}$ paru di Puskesmas Padasuka Kecamatan Cibeunying Kidul Kota Bandung dari 21 responden, didapatkan bahwa umur responden pasien $\mathrm{Tb}$ Paru di Puskesmas Padasuka Kecamatan Cibeunying Kidul pada tahun 2015 sebagian besar berusia 46-55 tahun yaitu sekitar 11 orang (54\%), dan berusia 26-35 tahun 6 orang $(25 \%)$. Kategori umur menurut Depkes RI yaitu, masa remaja akhir (17-25 tahun), masa dewasa awal (26-35 tahun), masa dewasa akhir (36-45 tahun), masa lansia awal (46-55 tahun), masa lansia akhir (56-65 tahun), masa manula (65 tahun keatas).

Hal ini sesuai dengan berbagai penelitian lain yang menyimpulkan penyakit Tb paru terutama pada usia produktif (Cofton, 1999; Reichman, 2000; Enarson, 2004). Sekitar $75 \%$ pasien $\mathrm{Tb}$ adalah kelompok usia yang paling produktif secara ekonomis (15-50 tahun). Diperkirakan seorang pasien $\mathrm{Tb}$ dewasa, akan kehilangan rata-rata waktu kerja waktu kerjanya 3 sampai 4 bulan. Hal tersebut berakibat pada kehilangan pendapatan tahunan rumah tangganya sekitar 20-30\%. Jika ia meninggal akibat $\mathrm{Tb}$, maka akan kehilangan pendapatannya sekitar 15 tahun. Selain merugikan secara ekonomis, $\mathrm{Tb}$ juga memberikan dampak buruk lainnya secara sosial stigma bahkan dikucilkan oleh masyarakat (Depkes RI,2011).

Hasil penelitan ini menunjukkan bahwa dengan jenis kelamin pasien $\mathrm{Tb}$ paru di Puskesmas Padasuka Kecamatan Cibeunying Kidul Kota Bandung didominasi oleh pasien Tb paru laki-laki sebanyak 15 orang (71\%) dan pasien $\mathrm{Tb}$ paru perempuan sebanyak 6 orang (29\%). Dalam penelitian lain yang dilakukan oleh Hayati (2011) dengan total responden 76 orang ditemukan responden terdiri dari 37 lakilaki $(48,6 \%)$ dan 39 perempuan $(51,3 \%)$. Proporsi responden laki-laki dan perempuan didapatkan hampir seimbang, bahkan perempuan sedikit lebih banyak. Di Negara berkembang, diperkirakan jumlah penderita laki-laki dan perempuan sama banyaknya, kendati data belumlah memadai. Di Indonesia kasus baru $\mathrm{Tb}$ hampir separuhnya adalah perempuan dan $\mathrm{Tb}$ membunuh sedikitnya dua kali lebih banyak perempuan dari pada kematian akibat kehamilan persalinan (Aditama, 2004).

Berdasarkan hasil penelitian terhadap 21 total responden di Puskesmas Padasuka Kecamatan Cibeunying Kidul Kota Bandung, ditemukan bahwa jumlah responden yang patuh terhadap pengobatan $\mathrm{Tb}$ paru lebih besar 
dibandingkan dengan responden yang tidak patuh. Responden yang patuh berjumlah sebanyak 16 orang $(76 \%)$, responden yang tidak patuh sebanyak 5 orang (24\%). Dalam penelitian lain yang dilakukan oleh Hayati, (2011) hasil penelitian terhadap 76 total responden di Puskesmas Kecamatan Pancoran Mas Depok, ditemukan bahwa jumlah responden yang patuh terhadap pengobatan TB paru lebih besar dibandingkan dengan responden yang tidak patuh. Responden yang patuh berjumlah 43 responden (56,58\%) sedangkan responden yang tidak patuh berjumlah 33 responden $(43,42 \%)$.

Kepatuhan dapat diukur dengan menggunakan dua definisi, yaitu definisi yang berorientasi pada proses dan definisi yang berorientasi pada dampak pengobatan. Indikator-indikator yang berorientasi pada proses menggunakan variable-variabel seperti penetapan janji untuk bertemu (antara dokter dan pasien) atau pengambilan obat digunakan sebagai ukuran kepatuhan. Sedangkan definisidefinisi yang berorientasi pada dampak menggunakan hasil akhir pengobatan, seperti angka kesembuhan sebagai salah satu indikator keberhasilan pengobatan Tb Paru (WHO, 2003 dalam Hayati, 2011). Alasan yang paling banyak diungkapkan oleh responden yang patuh adalah karena ingin cepat sembuh dari penyakitnya, bisa beraktivitas kembali seperti biasa sebelum sakit, dukungan dari keluarga responden dan informasi yang didapatkan dari petugas puskesmas sangat baik sehingga termotivasi untuk patuh meminum obat. Dukungan keluarga sangat penting untuk mendorong pasien agar patuh dalam meminum obatnya, memberi dorongan keberhasilan pengobatan dan tidak menghindari pasien karena penyakitnya (BPOM, 2006). Dukungan keluarga terhadap kepatuhan berobat pada pasien $\mathrm{Tb}$ paru yaitu dengan mendorong pasien agar patuh meminum obatnya, memberi dorongan keberhasilan pengobatan dan tidak menghindari pasien karena penyakitnya. Bila dukungan keluarga mengingatkan agar meneruskan pengobatan secara teratur bagi keluarga yang sakit tidak diberikan bagi pasien penyakit kronis yang membutuhkan pengobatan yang lama dapat terjadi kegagalan pengobatan pasien (Hutapea 2004).

\section{KESIMPULAN}

Dapat disimpulkan bahwa dari total responden sebanyak 21 orang dapat ditemukan responden yang patuh sebanyak 16 orang (76\%), namun masih ditemukan responden yang tidak patuh sebanyak 5 orang (24\%).

\section{REFERENSI}

Aditama, T. Y. Tuberkulosis paru masalah dan penanggulangannya. UI Press, Jakarta.

Departemen Kesehatan Republik Indonesia. ( 2008). Pedoman penaggulangan nasional TBC. Jakarta: Depkes RI.

Departemen Kesehatan Republik Indonesia. ( 2011). Pedoman penanggulangan nasional TBC. Jakarta: Depkes RI.

Departemen Kesehatan Republik Indonesia. ( 2013). Laporan Nasional Riset Kesehatan Dasar. Jakarta: Pusat penelitian pengembangan kesehatan.

\section{DEPKES. (2013). Riset Kesehatan Dasar} 2013. Diakses dari http://depkes.go.id/download/riskesdas 2013/hasil\%20Riskesdas\%202013.pdf diakses pada 12 maret 2015 .

Dinas Kota Bandung. (2011). Profil Kesehatan Kota Bandung. Bandung.

Badan POM. (2006). Kepatuhan Pasien faktor penting dalam keberhasilan terapi. Jakarta: Badan POM Republik Indonesia. 
Hayati, A. (2011). Evaluasi kepatuhan berobat penderita tuberculosis paru tahun2010-2011 dipuskesmas pancoran mas depok.(skripsi). Sekolah Sarjana, Universitas Indonesia, Jakarta.

Tahan P. Hutapea. (2006) Pengaruh dukungan keluarga terhadap kepatuhan minum obat anti tuberkulosis RSUD Dr. saiful anwar malang.

http://jurnalrespilogi.org/jurnal/april09/ dukungan\%20keluarga.pdf diakses pada tanggal 12 juni 2015.
World Health Organization. (2003). Adherance to long-term therapis evidence for action. Genewa: World Health Organization. 